Historic, Archive Document

Do not assume content reflects current scientific knowledge, policies, or practices. 



\section{Standard}

Gardening Books

For those who seek practical, worthwhile advice. Attractive covers, clear type, high class teaching illustrations and the best of presswork and binding mark these volumes.

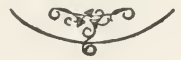

CADWELL \& JONES 1084-1086 Main Street Hartford, Conn. 
$W^{E}$ believe we are within the truth in our statement that PRACTICAL LANDSCAPE GAR$D E N I N G$ has enjoyed larger sales than any other book on the same subject ever placed on the market. Its preciseness, simplicity, comprehensiveness, and price, account for its success.

\section{Practical \\ Landscape Gardening}

By ROBERT B. CRIDLAND

For the owner of a modest home

It tells how to plan and plant from a $20 \mathrm{ft}$. plot up.

It gives detailed sketches showing where to place your flower, Rose, wild or rock garden.

It has planting plans telling exactly what varieties to plant for best effects.

It gives working plans showing how to construct walks, drives, pergolas, terraces, pools, fountains, garden seats and rustic houses.

It illustrates home ground surroundings, showing correct and incorrect methods.

It tells in detail all about lawn making, gutters, catch basins, roadways.

Its pictures place before you the explanation of practically every problem confronting the home builder and owner.

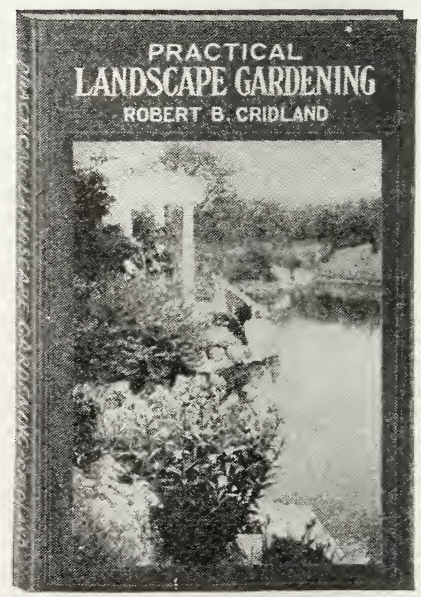

Contains 91 photographic illustrations, 67 sketches and 33 plans, 19 of which are planting plans accompanied by planting keys. The type is large and clear; the paper is enamel; the binding durable. The color plate on front cover is irresistibly attractive; it portrays a wonderful landscape scene.

Price, cloth bound, $\$ 2.65$, postpaid. 
A WELL known Southern lady, herself a landscape architect and planter, with a fine garden of her own, has written the BLOSSOM CIRCLE OF THE YEAR IN SOUTHERN GARDENS with a view to encouraging Southern women to have gardens of pleasure. This book is a worthy one and will prove most helpful to all in the South.

\title{
The Blossom Circle of the Year in Southern Gardens
}

\author{
By JULIA LESTER DILLON
}

For Beautifying Home Grounds in the South.

First and only book dealing exclusively with methods, materials and problems of southern ornamental gardening. It has been written by a woman who knows at first hand your problems and your aims, and who, from long practical experience, knows how to help you solve the former and attain the latter.

\section{Scope and Contents}

Introduction : Broad Leaved Evergreens - For Every Garden. Ornamental Hedge Planis - For Every Gardener. Azaleas and Camellias - For All Who Love Them. Coniferous EvergreensFor Beauty and Accent. Old-Fashioned Roses- How to Grow Them. Making a Rose Garden-To Live in and Love. March ActivitiesThe beginning of the Summer Garden. April Leaves from My Garden Book. May Work - For Fall Glory. 'Taking Stock of the Garden - Under June's Sunny Skies. July Planting-For Permanent Effects. Fighting the Midsummer Pests. Dependable Perennials - When to Plant Them. October Glories-And October Work. Sweet Peas-For Spring Blossoming. Deciduous Shrubs; Vines; Southern Lawns; Flowering Trees, etc.

2uU pages, cloth bound, illustrated. Price, $\$ 2.65$, postpaid. 
ONE of the greatest pleasures in life to the enthusiastic plant grower is an understanding of how plants are produced and multiplied. PRACTICAL PLANT PROPAGATION tells the "How."

\section{Practical \\ Plant Propagation}

By PROF. ALFRED C. HOTTES

Appeals to everyone who has to do with seeds and plants, whether amateur or professional

An exposition of the art and science of increasing plants as practiced by the nurseryman, florist and gardener.

The text is brief and to the point. No lengthy discussions, but facts are tersely stated, so that the busy propagator may get the point quickly and return to the propagation of his plants.

All a mateurs have an intense desire to propagate those plants which they admire. In this book is told in simple terms how to graft fruit trees, make cuttings and layers, and sow the seeds which are often difficult to germinate.

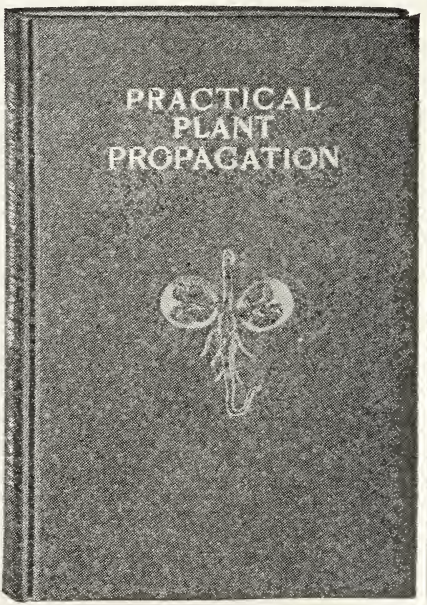

A book of this

character has never been of more interest than at present, as no longer can we look to Europe for our finer plants.

Profusely illustrated with halftones and line cuts. Price, cloth bound, $\$ 2.15$, postpaid. 
THAT fruit has the finest flavor which one picks on his own home grounds. Embellish your property with fruits, both small and standard, and be guided in their planting by the HOME FRUIT GROWER. Even if you have fruits on your place now, this book will help you, through the author's experience, to more satisfactory crops.

\section{HOME FRUIT GROWER}

By M. G. KAINS

For the amateur who seeks to grow high quality fruits

The author was particularly well fitted to have written this book, having been reared on a fruit plantation in a village where for more than half a century the leading hobby has been high quality fruit growing for family use. With this standard of excellence he has united the best modern methods of securing choice specimens - methods little practiced, or even unknown, in his boyhood days -tillage, spraying, thinning, fertilizing, cover cropping, preventing frost injuries, low heading, rational pruning-

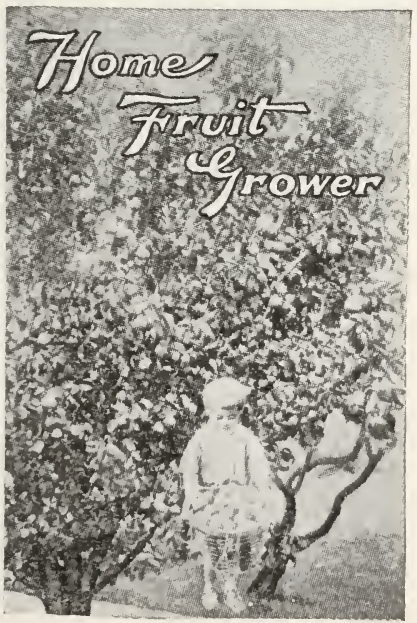
cach simple in itself and each conducive to the production of an abundance of the best fruit.

Heavily illustrated with teaching pictures. Beautiful cover in four colors. Price, cloth bound, $\$ 1.65$, postpaid. 
A LL standard works on landscape gardening $A$ have to be somewhat alike in their definitions of first principles and the general rules governing development. The outstanding features of the Complete Home Landscape, making it entirely different from other works on the subject, are the Selected Plant Lists for Various Purposes, embracing 24 collections of named plants for 24 different conditions, and the many wonderful hand drawn illustrations which render the text so readily understood.

\section{The Complete Home Landscape}

By ARTHUR J. JENNINGS and LEONARD H. JOHNSON

A complete guide to the planning, construction and planting of the garden and grounds of the average home. A book that can and should be used by every home maker, every real estate development concern and every nurseryman, retail grower or landscape gardener who has to do with the planting and beautification of city, suburban, small town or country homes.

Here are a few of the subjects covered by the different chapters:

Principles of Design, Styles of Landscape Development, Locating the House, Grading, Making the Lawn, Drives and Walks, Walls and Wall Building.

Rock Gardens and Water Gardens, Objects of Planting, The Planting Plan, Principles of Plant-

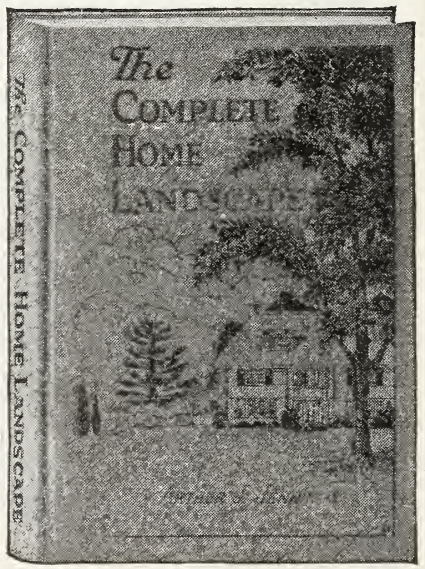
ing.

Pruning and Winter Protection, Color in the Garden, Formal Gardens, Rose Gardens, and Garden Accessories.

178 pages, 114 illustrations. Price, cloth bound, $\$ 2.65$, postpaid. 
O enjoy the reputation of being an adept in the
arrangement of flowers in your home means quite a little to both yourself and visitors. Prof. White's book, so far as we know, is the first one to furnish this desirable social information.

\section{The Principles of Flower Arrangement}

By PROF. E. A. WHITE

For the amateur and the professional.

When one carefully studies the work of people successful in flower arrangement, it is found that they usually follow in their compositions principles which are as definite as are those governing the worker with oils and water colors. The author has for years analyzed the work of students and others to determine the dominant principles that make one person's work more effective than another's, and this book is the result of his observations, the fundamental principles of flower arrangement. The chapters cover the Decorative Value of Flowers, Plant Material for Decorative Purposes, Receptacles for Cut Flowers and Potted Plants, Japanese Flower Arrangement, Tones, Measures and Shapes, Notan and Color, Color Harmonies,

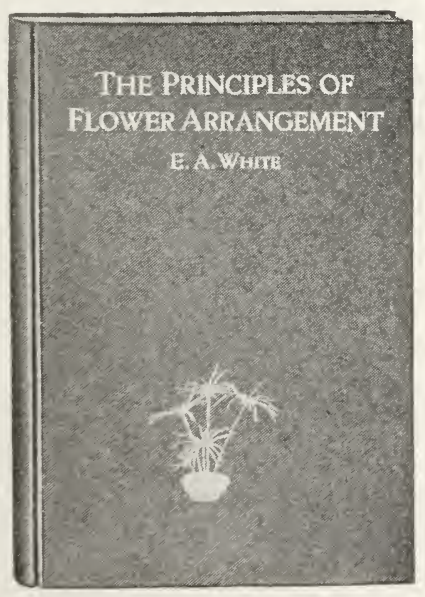
Church, Hall or Reception Room Decorations, Table Decorations, Flowers for Personal Adornment, Baskets an.1 Sprays, Wreaths and Other Designs, Practical Exercises in Flower Arrangement.

200 pages, profusely illustrated. Price, cloth bound, $\$ 2.65$, postpaid. 
A WELL known horticulturist has said that he is sometimes tempted to believe that climbers are the most valuable of all ornamental plants because they are the only ones that have the power to transform ugliness into beauty.

\title{
A Little Book of Climbing Plants
}

\author{
By ALFRED C. HOTTES
}

The author has produced a truly remarkable book. one that will take its place among the standard horticultural books of the age. The only book obtainable combining all climbing plants, of whatsoever nature, in the one volume. The chapters include:

The Uses of Climbers; The Abuses of Climbers; The Objections to Climbers; How Plants Climb; General Cultural Notes; Pruning and Training; Propagation; Insects and Diseases; Garden Enclosures and Plant Supports; Lists of Vines for Many Purposes; Hardy Climbers, Woody and Herbaceous Perennials; Climbing Roses; Annual Climbers; Conservatory Climbers and Creepers; Ground Covers; A Key to Common Vines; A Glossary of Terms Used; Index to Meaning of

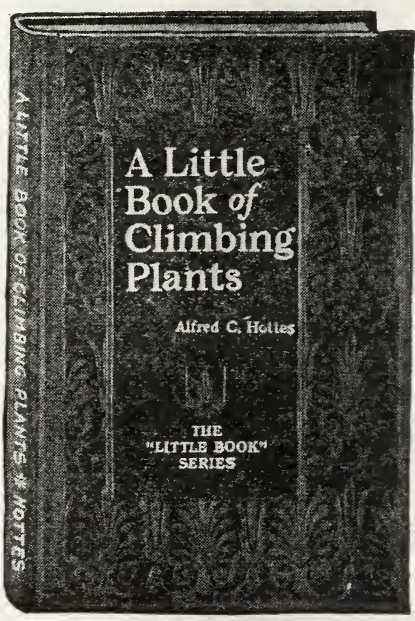
Species Names;

Table of Climbers, Trailers and Ground Covers; General Index.

Highly illustrated. 250 pages. Price, cloth bound, $\$ 1.90$, postpaid. 
WHEN one considers the low cost of seed, coupled with the minimum of effort required to mature, is it any wonder that annuals are among our most popular favorites of today?

\section{A Little Book of Annuals}

By PROF. ALFRED. C. HOTTES

For the amateur and professional. Companion book to the Little Book of Perennials.

A reliable guide through the season of annual bloom. Among the choicest flowers scattered over the earth are some whose lives are short. They sprout from seed, grow, flower, produce seed in their turn-and then die. These are the annuals, and Prof. Hottes through his book opens the door to greater success with these charming flowers. Over 100 separate species are described with full directions for their culture and uses.

Chaptersinclude: The Use of Annuals, Ordering Seeds, Classes of Annuals, Seed Sowing, Transplanting, Pinching, The Hoe vs. The Hose, Watering vs. Sprinkling, Annuals and Shade, Fall Sowing and SelfSown Annuals, Hotbeds and Coldframes, Annual

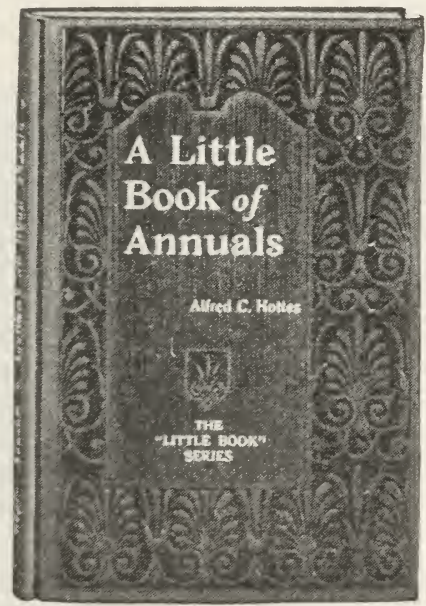
Flowers and Their

Uses, A Chain of Ten Links, Annuals of Merit, Ornamental Grasses, Everlastings, Decorative Seed Pods, Annual Vines, etc.

Price, cloth bound, $\$ 1.65$, postpaid. 
A BOUT 30 years ago a great nursery came to grief because it had anticipated by 15 years the public cail for perennials. Today hardly a sufficient number can be raised to supply the popular demand. This LITTLE BOOK OF PERENNIALS by Hottes will post admirers of perennials - the most durable of all our border plants-on how to grow them and how to enjoy them.

\section{A Little Book of Perennials}

By PROF. ALFRED C. HOTTES

For the amateur and professional. Companion book to the Little Book of Annuals.

Devoted to the general principles of growing, using, selecting and propagating perennials, followed by a number of comprehensive lists of perennials suited for different locations and purposes. The most important and useful representatives of this popular class of garden plants - to the number of over 125 separate speciesare discussed individually, together with their culture and requirements.

A tabular cultural index, giving species or variety, height, flowering period, color, etc., adds to the value of the book.

The volume is marked by the liberal use of illustrations and by the eminently practical language that makes Prof. Hottes' writings both interesting and instructive for amateur as well as professional.

Price, cloth bound, $\$ 1.65$, postpaid. 
THOUSANDS of women are daily seeking for information on how to care for their house plants. MILADY'S HOUSE PLANTS will give them this information, for the book was written by a florist who has had over forty years experience in catering to women interested in just this phase of floriculture.

\section{MILADY'S HOUSE PLANTS}

By F. E. PALMER

For those seeking success with plants in the home

Tells how to care for Palms, Ferns, Rubber Plants, Fuchsias, Jerusalem Cherries and scores of other popular house plants, together with advice about the best plants to grow indoors.

Wh a t instructions to follow for potting, drainage, watering, temperature, sunlight, air, and other details.

What flowers and plants are adapted for hanging baskets and window boxes; how to arrange effective table centerpieces and other indoor floral decorations. How to grow bulbs in bowls; full directions on how to propagate the various house plants.

Profusely illustrated with about 100 instructive pictures, the majority of them taken exclusively for this book.

Price, cloth bound, $\$ 1.10$, postpaid. 
THE sale of over 40,000 copies of this Standard T-Guide is proof positive of the complete way in which everything having to do with the exterior of a country home is covered in its 384 close pages.

\section{Garden Guide}

A complete handbook for the amateur gardener

Fourth Edition

384 pages and over 275 teaching illustrations with beautiful cover in four colors

The gem of gardening literature. Over 40,000 copies sold throughout the United States and Canada.

Garden Guide has wonderful chapters devoted to the Vegetable, Flower and Fruit Gardens, with practical layouts and planting plans.

It tells you in full about how to prepare and fertilize your ground how to distinguish and get rid of insect pests.

All the flowers and bulbs with planting plans; the lawn, ornamental trees and shrubs, vines, water plants.

How to prune your plants; how to propagate plants; how to construct hotbeds and forcing frames; how to spray; about tools,

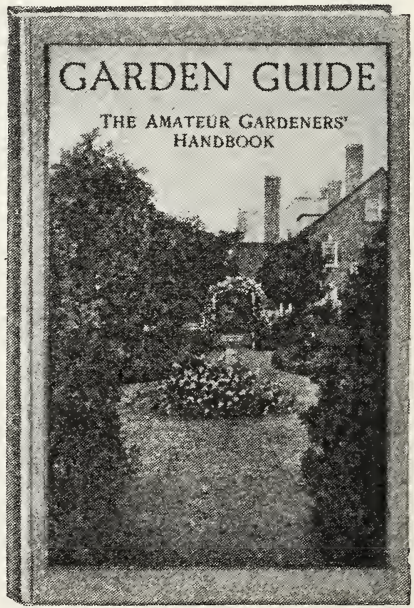
rustic furniture, birds of the garden, canning, Winter storage of food and plants, etc.

Covers every step from spading the ground to preserving the harvest.

Price, cloth bound, $\$ 1.65$, postpaid. 